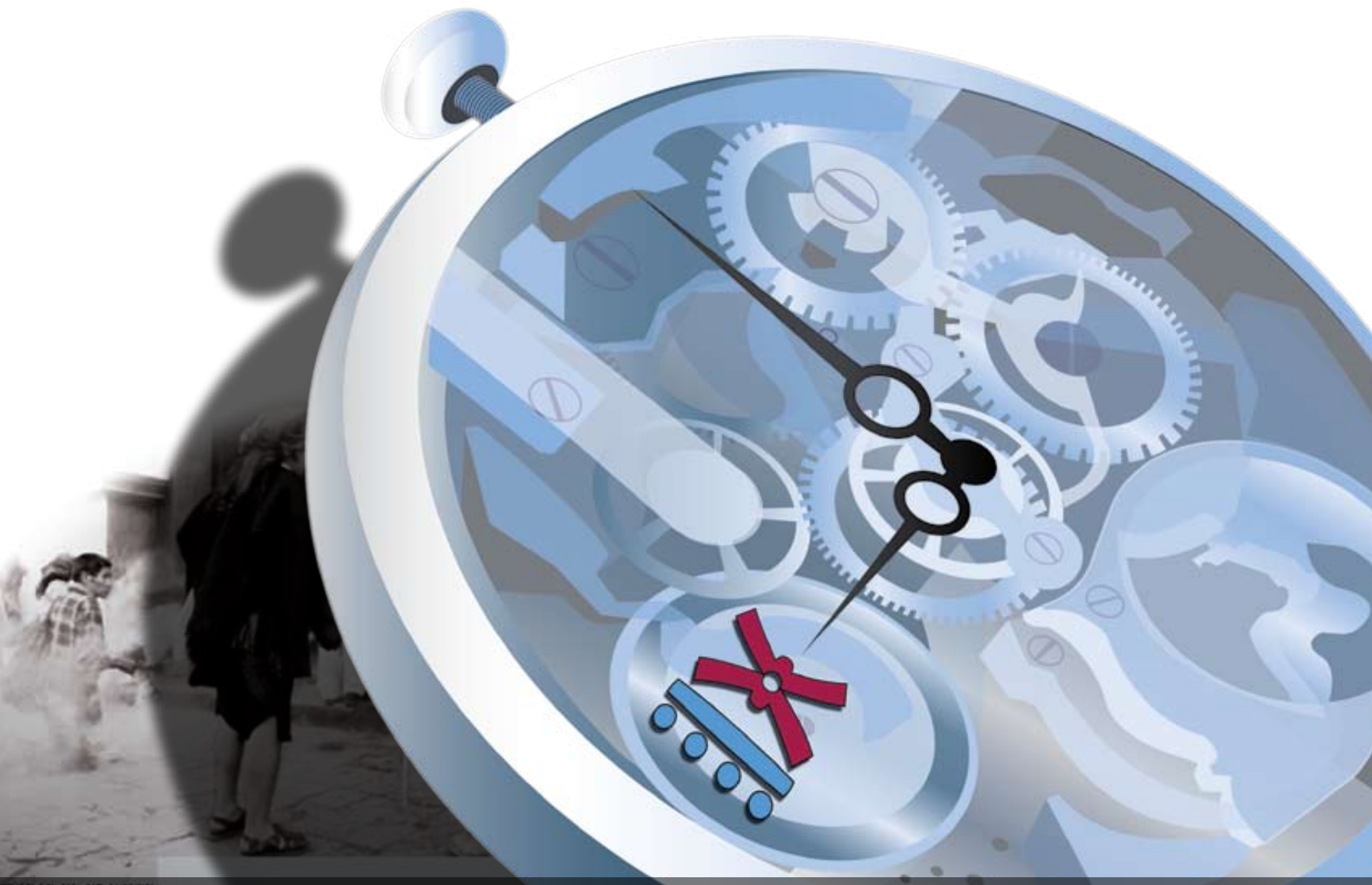

$9^{\circ}$ C O N G R E S O 2. CENTROAMERICANO DE H IS TO R I A
Universidad de Costa Rica

ISSN 1409-469X

Fecha de recepción: 15 de mayo 2008 Fecha de aceptación: 30 de mayo 2008

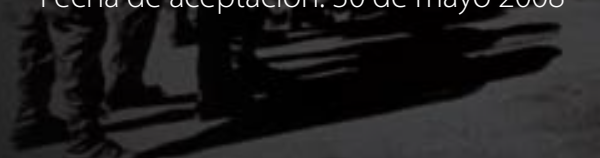

El Antiguo Régimen en Costa Rica:

Imaginarios de una organización socio-política (1600-1718)

Miembros del Consejo Editorial:

Dr. Ronny Viales, Dr. Juan José Marín

Editores Técnicos:

Allan Fonseca, Andrés Cruz, Gabriela Soto

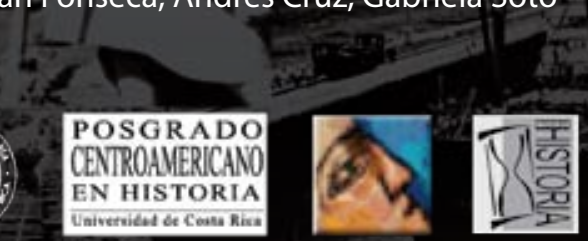


Indexaciones: Repositorio de Revistas UCR, DIALNET, Latindex, REDALYC Directorio y recolector de recursos digitales del Ministerio de Cultura de España, Directory of Open Access Journals. Diálogos Revista Electrónica de Historia ISSN 1409- 469X. Número especial 2008. Dirección web: http://historia.fcs.ucr.ac.cr/dialogos.htm

\title{
El Antiguo Régimen en Costa Rica: Imaginarios de una organización socio-política (1600-1718)
}

\author{
Eduardo Madrigal Muñoz
}

Doctor en Historia por la Universidad de Costa Rica y la Universidad de Toulouse II-Le Mirail, investigador del Centro de Investigaciones Históricas de América Central, CIHAC-UCR. Correo electrónico edmadm@yahoo.es . 


\section{Introducción:}

Las ideologías, los intereses, las visiones de mundo y las luchas de poder son variables fundamentales que se deben estudiar si se quiere entender el funcionamiento de un sistema político. ¿Cuáles eran los que primaban en Costa Rica durante los siglos coloniales? Cuando de estudiar lo político en las sociedades coloniales hispanoamericanas se trataba, la historiografía tradicional dio primacía al estudio de la legislación y las instituciones políticas indianas. ${ }^{1}$ Superado su enfoque por las diferentes corrientes de la Historia Social a fines del siglo XX, el estudio de estas sociedades giró y se dirigió más que todo a sus componentes socio-económicos. Actualmente, nuevas corrientes historiográficas, imbuidas de un interés incrementado por estudiar lo cultural y las antiguamente llamadas "mentalidades colectivas" e influidas por nuevos enfoques teórico-metodológicos, han venido haciendo aportes en lo referente a los valores y visiones de mundo que impulsaban a los seres humanos de este período a estructurar su accionar. Con ello han abierto un paso para el estudio de las variables antes consideradas "superestructurales", dentro de las que se contaban los simbolismos y las representaciones sociales, así como lo referente a las instituciones políticas.

Como resultado, ha sido señalado que el Antiguo Régimen era una sociedad corporativa donde los hombres se diferenciaban entre sí por criterios socio-jurídicos -como la pertenencia a estamentos y castas-, y que se organizaba en cuerpos sociales cuyo objetivo era procurar bienestar y autogobierno a la sociedad. ${ }^{2}$ La religión era, para este tipo de colectividad, columna vertebral estructurante para dar sanción ideológica al sistema político. ${ }^{3}$ Dentro de este contexto, las monarquías de la época, pese a sus esfuerzos centralizadores, carecían de mecanismos para llegarle directamente a la población de sus reinos y debían, por tanto, depender de la amplia gama de corporaciones sociales existentes para poder hacerse obedecer en un universo de poder político atomizado. ${ }^{4}$ Debido a lo anterior, las elites locales desempeñaron un papel fundamental como interlocutores de las monarquías para garantizar el ejercicio del poder real en los diversos contextos locales.

La presente ponencia tiene como objetivo averiguar cómo se manifestó este orden de cosas en una provincia apartada y en definitiva periférica del Imperio Español y qué tejido de valores e imaginarios colectivos fue lo que le dio sustento.

\section{Recordemos los viejos textos de J.M. Ots Capdequi, de Clarence Haring y de J.H. Parry, por ejemplo.}

2 José María Imízcoz Beunza. “Communauté, réseau social, élites. L’armature sociale de l’Ancien

Régime" en Réseaux, familles et pouvoirs dans le monde ibérique à la fin de l'Ancien Régime, ed. Juan Luis Castellano y Jean-Pierre Dedieu (París: Éditions du CNRS, 1998) 31-66. Annick. Lempérière, Entre Dieu et le roi, la république (Paris: Les Belles Lettres, 2004)

3 Jaime Contreras, "Historia y teología. Consideraciones sobre cultura religiosa en el mundo hispánico del Antiguo Régimen. Redes y estructura social.” Exposición realizada en el coloquio "Encuentros por la Historia”, III edición, Heredia, Universidad Nacional, 6 de febrero de 2004.

4 Jean-Paul Zúñiga, “Cabildo colonial et formation de l'élite: le cas de Santiago du Chili (1655-1675)”, Recherches sur l'étatdans le monde ibérique (París: Presses de l’Ecole Normale Supérieure), 1993: 12-21. 
El campo de estudios: la “armadura política del Antiguo Régimen” y la institución del cabildo:

Desde mucho tiempo atrás, las elites coloniales hispanoamericanas han atraído la atención de la historiografía americanista y su estudio ha mostrado rostros harto variados. Recientemente, partiendo de una renovación historiográfica, nuevas tendencias se han ocupado de echar a andar nuevos enfoques teórico-metodológicos donde la metodología prosopográfica y la teoría de las redes sociales han desempeñado un papel protagónico. ${ }^{5}$ En nuestro caso particular, nosotros nos hemos sumado a estas nuevas tendencias, haciendo un estudio prosopográfico y de redes sociales sobre el grupo dotado de poder político, es decir, de todos aquellos individuos que detentaron algún puesto de gobierno colonial en la ciudad de Cartago, capital colonial de la provincia de Costa Rica. El grupo escogido fue originalmente el de los integrantes del cabildo de la ciudad pero, posteriormente, hubo de ser ampliado a todos los integrantes de las otras instituciones vigentes en la época.

Tal interés nos puso de frente con la necesidad de aclarar y analizar los criterios sociojurídicos de pertenencia a la institución del cabildo, debido a la necesidad metodológica de delimitar los contornos del grupo a estudiar para comprender sus dinámicas. Con todo, el solo estudio de las leyes formales no parecía suficiente para agotar el campo de análisis del proceso de construcción de un grupo socio-institucional dirigente. Por ello, nos pareció necesario incorporar al análisis del enmarcamiento legal y de las bases jurídico políticas de las instituciones un estudio concienzudo de las concepciones simbólicas y de las prácticas sociales que rodeaban los procesos de reclutamiento de los grupos dotados de poder político en la época.

La primera constatación que se desprende de la observación del Derecho de la época es que en el Antiguo Régimen no existía el moderno concepto de división de poderes, de modo que las facultades ejecutivas, legislativas y judiciales estaban concentradas en manos de la monarquía y todas sus instituciones políticas las ejercían simultáneamente.

Por otra parte, aparece ante nuestros ojos que era este un universo donde el poder no estaba distribuido de manera racionalizada, bajo la forma de una pirámide de jerarquías como estamos habituados a ver en el Estado Moderno y, antes bien, las instituciones políticas del Antiguo Régimen se estructuraban de acuerdo a un criterio de colegialidad. ${ }^{6}$ Esta característica respondía a la preocupación de la sociedad de esta época por evitar la concentración del poder en manos de un solo individuo, lo que podía conducirle a cometer abusos. Tal práctica era así una consecuencia del propósito político de esta sociedad de garantizar la paz y la transparencia

$5 \quad$ Michel Bertrand (coord), Configuraciones y redes de poder: un análisis de las relaciones sociales en América Latina (Caracas: Fondo Editorial Tropikos, 2002); Michel Bertrand, Grandeur et misère de l'office, les officiers de finances de Nouvelle-Espagne (XVII-XVIII siècle) (París: Publications de la Sorbonne, 1998); JeanPaul Zúñiga, Espagnols d’ outre-mer. (Paris: Éditions de l’EHESS, 2002); José Manuel Santos Pérez, “Las élites de Santiago de Guatemala y el cabildo colonial (1700-1770)”, Revista de Historia (San José: EUNA y EUCR) 38 (Julio-Diciembre, 1998): 87-111.

6 Lempérière, Annick, 31 
en la vida de la "República Cristiana”. De este modo, lejos de favorecer un esquema de funcionamiento jerárquico en cadena, las diferentes instituciones políticas aparecían como cuerpos sociales de carácter colectivo y con funciones diversas, destinados al gobierno de los cuerpos sociales mayores de cada localidad. El cabildo en particular aparecía como el representante último de todos ellos ante la monarquía. ${ }^{7}$

Dentro de este contexto, todo cabildo colonial estaba constituido por dos subdivisiones internas: la “justicia” y el "regimiento”. La primera estaba integrada por los jueces conocidos como “alcaldes ordinarios” y "alcaldes de la Santa Hermandad” (denominados como los “justicias” en el vocabulario político de la época), que se encargaban de la administración de justicia en el perímetro urbano y en las comarcas de la periferia respectivamente. Otros oficiales como el "procurador síndico" y el "mayordomo de propios", se encargaban de la defensa de los intereses de la población ante el cabildo y de la administración de las finanzas de la institución, respectivamente. Todos estos oficiales eran nombrados anualmente.

Por su parte, el "regimiento" estaba constituido por ediles ("regidores") permanentes que tenían bajo su responsabilidad los asuntos de la administración urbana en todas sus diversas facetas. Estos ediles constituían, entonces, el núcleo de la institución municipal de la época, pues eran los más estables de todos y además los encargados de elegir cada año a las demás autoridades del cuerpo social de su jurisdicción. Los regidores compraban sus puestos a la corona y los ejercían en régimen de perpetuidad.

Los criterios de pertenencia al cabildo; ceremoniales y distinciones:

Por otra parte, durante el período colonial, la pertenencia a un cabildo y a las instituciones políticas en general estaba ligada a un conjunto de criterios de posición social como la nobleza y la riqueza. Esto era así porque la sociedad de la época se estructuraba como una sociedad de estamentos y de castas étnicamente delimitadas, donde la desigualdad de los individuos era un hecho reconocido, legitimado y aceptado. ${ }^{8}$ Este régimen de estructuración socio política estaba consagrado así en las leyes formales que establecían un conjunto de regulaciones que apuntaban a consolidar y a perpetuar en el mando a los miembros de los grupos más altos de la sociedad. Implícito en este conjunto de leyes formales, había todo un abanico de códigos sociales que excluían a las mayorías sociales del acceso al poder político y provocaban que este fuese de acceso exclusivo para el grupo social de los privilegiados.

En efecto, los puestos políticos poseían en esta época una connotación de relación personal de servicio entre el rey y sus vasallos. En consecuencia, estos eran vistos como privilegios otorgados por la corona en función de los méritos y servicios prestados por vasallos

$7 \quad$ Ibid , 30

8 Imízcoz Beunza, José María. “Communauté, réseau social, élites. L’armature sociale de l’Ancien Régime.” En: Castellano y Dedieu, 31-66. 
fieles. Los puestos políticos revestían, entonces, la función de un premio en doble sentido y a dos tiempos. Por un lado, se trataba de otorgar honores y fuentes de riqueza a los súbditos fieles de la corona para que pudiesen así mantener su posición de preeminencia social. Por otro, el sistema apuntaba a garantizar el compromiso futuro de los vasallos de continuar sirviendo con fidelidad.

Como se puede entrever, estos hechos eran totalmente reconocidos por la sociedad y se consideraban legítimos, por lo que no era en modo alguno objeto de rechazo el que sirviesen a sus propietarios para dotarse de un medio de adquirir riqueza, poder y prestigio social, en otras palabras, para sacarles provecho.

Por ende, esto explica la práctica de la venalidad, de vender los puestos. ${ }^{9}$ Vendiendo los puestos políticos la corona española no hacía sino cobrar a los titulares por una porción de las ganancias que iban a obtener de ellos. Esta práctica, creó lo que se llamaba en la época los "oficios vendibles y renunciables." Evidentemente, esto tuvo por efecto la exclusión masiva de todos aquellos que no podían pagar por puestos políticos y ello conllevó la transformación del poder político en privilegio exclusivo de aquellos que podían comprarlo: un proceso de elitización de la política.

Tal práctica servía también para dotar de recursos económicos a la corona, que los necesitaba urgentemente para financiar las guerras europeas en las que se veía envuelta en la época. ${ }^{10}$

Otra finalidad del sistema venal de concesión de puestos era que volvía visibles los códigos de soberanía del rey y consecuentemente, de la sumisión a él de sus súbditos, pues reforzaba la imagen de la corona como única fuente de poder y de legitimidad.

Fue así como, en el Nuevo Mundo, desde el inicio, el acceso a los puestos políticos se circunscribió a un grupo muy restringido de individuos, especialmente a aquellos que habían participado en el proceso de conquista. Más tarde, este privilegio se extendió a todos los que podían pagar por los puestos, lo que abrió la posibilidad a otros grupos e individuos de participar en el ejercicio del poder. El poder de nombrar las primeras autoridades municipales durante el período de conquista estaba en las manos de los adelantados de conquista pero, después de este período, fue asumido por las autoridades reales. Los primeros en ser nombrados en puestos municipales en este período tendían a ser, evidentemente, los conquistadores de más renombre o los más próximos a los capitanes de conquista, aunque luego, los puestos de cabildo empezaron a venderse al mejor postor por la corona desde 1591 . Los orígenes de esta práctica remontaban al pasado medieval. ${ }^{11}$

Además, con el fin de volverlos más atractivos, la corona añadió a la venta de los oficios la posibilidad de renunciarlos nombrando un sucesor escogido por el titular, creando así una

9 Práctica consagrada en la Ley I, Título XX, Libro VIII, titulada "De la venta de oficios"

10 Webre, Stephen. The social and economical basis of cabildo membership In XVIIth centuryGuatemala.

(Tulane: tesis doctoral, 1980), cap.1.

11 Ibid. 
suerte de "herencia” legalizada de los puestos. Con el objetivo anterior, la corona añadió también a algunos regimientos privilegios particulares tales como las funciones de policía en las ciudades o en los campos, la función de portar el estandarte real en las festividades cívicas y religiosas, etc., creando de esta manera los así llamados "oficios de privilegio", que costaban, por demás, precios más altos que los regimientos simples. ${ }^{12}$

Las condiciones requeridas por la corona para la venta de los oficios tuvieron también por resultado su limitación al acceso de solo un grupo de individuos poderosos. Por ejemplo, era requisito que el interesado hiciese una solicitud formal de compra del puesto ante la Audiencia local, la cual echaba a andar el trámite, cuyas etapas estaban muy lejos del acceso de gentes no dotadas de medios, los cuales incluían la gestión de apoderados para los compradores procedentes de regiones distantes al asiento del supremo tribunal. Después de la venta, se requería además el pago de un impuesto real (la "media anata") y de fianzas, además del precio mismo del puesto.

Finalmente, la toma de posesión de los cargos se revestía de todo un ceremonial destinado a subrayar los simbolismos de soberanía y de sumisión del monarca y de los vasallos, así como los de la supremacía del cuerpo de regidores sobre el cuerpo social más amplio. Este ceremonial incluía un ritual de juramento del titular y de aceptación de los títulos reales aportados por este por los otros miembros del cabildo.

Dado que la organización del poder en esta época no respondía a criterios racionales, la cantidad de regidores de cada ciudad hispanoamericana variaba y cada ciudad contaba con sus propias costumbres y privilegios. El derecho de Indias estipulaba, sin embargo, que en las capitales virreinales el número de regidores no debía exceder los doce y en las ciudades de provincia debían ser un máximo de seis. ${ }^{13}$ Con todo, si estas cifras variaban en las ciudades coloniales hispanoamericanas, en Cartago fue respetada y el número de regidores fue siempre de seis. Entre ellos se contaban los regimientos de privilegio ("oficios de privilegio") que eran el alférez real, el alguacil mayor, el alcalde mayor provincial de la Santa Hermandad y el depositario general, así como dos regimientos simples.

Los regidores se sentaban, hablaban y participaban de las actividades públicas del cabildo en este orden estricto de precedencias pues era un principio fundamental de las costumbres del Antiguo Régimen que se respetasen las jerarquías sociales de todas suertes, como un mecanismo para resguardar la paz en la república. ${ }^{14}$ Además, un criterio de antigüedad se aplicaba para definir la precedencia si los puestos existentes no permitían siempre que se respetase el orden convencional. Así, el más antiguo de los regidores ("regidor decano”), disfrutaba de una posición de alto respeto en la corporación.

\footnotetext{
$12 \quad$ Ibid

13 Ley II, Título X, Libro IV de la Recopilación de 1680.

14 Lempérière, 84
} 
La venta de los cargos:

En cuanto a los precios de los oficios, parece desprenderse de la documentación que los más codiciados, aquellos que tendían a presentar los precios más elevados, eran aquellos que concedían a sus titulares el poder de ejercer coerción, tales como el de alguacil mayor o el de provincial de la Hermandad. ${ }^{15}$ El puesto de alférez real era codiciado porque actuaba como el regidor principal del cabildo pues era él quien portaba el estandarte real en las fiestas urbanas y, por ende, ello le dotaba de un gran prestigio y visibilidad social. Otros puestos como el de depositario general o los de regimiento simple eran ciertamente menos codiciados que los otros, pero no totalmente marginados. Pues abrían también la posibilidad de tener acceso a fuentes de enriquecimiento. No obstante, los precios de los oficios de cabildo en la Costa Rica colonial siempre fueron significativamente más bajos que los de la mayoría de las ciudades hispanoamericanas de la época, debido sin duda al carácter marginal de la provincia en el contexto del Imperio Español.

Por otro lado, dado el fuerte carácter de compromiso personal entre rey y súbditos que revestían los puestos de cabildo en la época, los precios de los regimientos dependían directamente de los términos de la relación personal entre monarca y vasallo. Ello equivale a decir que, cuando se vendía un cargo de cabildo a un particular interesado, lo que operaba verdaderamente para fijar el precio no era un valor abstracto de mercado, fijado por oferta y demanda, sino la importancia subjetiva que la corona y el interesado atribuían cada uno por su lado al puesto, según la importancia de la localidad. De esta manera, los precios de los regimientos podían fluctuar según varios factores. Para empezar, desde fines del siglo XVII, la Audiencia de Guatemala adoptó el hábito de fijar unilateralmente un precio mínimo por debajo del cual no vendía los cargos. De todas maneras, aún antes de eso ciertas reglas sociales parecen haber gobernado la conducta de los actores. Por ejemplo, parece muy frecuente que los candidatos se sentían obligados a ofrecer precios más elevados que sus predecesores, quizá por un asunto de pudor social, y cuando había disputas por los puestos. Cuando esto sucedía, la tendencia más común parece haber sido la de doblar la cantidad originalmente ofrecida por el rival o al menos aumentarla en un 50\%, con la intención de sobrepasarlo. Al final del trámite, con frecuencia los ganadores mejoraban la cantidad originalmente aceptada por la corona en un buen porcentaje. También, la práctica de "heredar" los puestos a candidatos elegidos directamente por los titulares contribuía a alterar los precios, pues la corona española había dispuesto que, cuando se daba esta situación, el nuevo titular debía pagar tan solo un tercio del valor pagado por su antecesor.

Siempre en relación con los precios de lo puestos y en atención a un tema que ha sido importante para la historiografía sobre cabildos hispanoamericanos, no se observa en la provincia colonial de Costa Rica durante el período estudiado ningún fenómeno de "colapso del mercado" como los que han sido señalados por numerosos autores para otras regiones

15 José Manuel Santos Pérez, Elites, poder local y régimen colonial: el cabildo y los regidores de Santiago de Guatemala 1700-1787, (Cádiz: Servicio de Publicaciones de la Universidad de Cádiz, 1999), 69 
de Hispanoamérica. El único colapso constatado es el que se opera después de 1718, luego de una larga disputa entre los miembros del cabildo y un "juez visitador" de la corona, los regidores fueron forzados a dejar sus cargos porque no habían terminado de pagarlos y estaban involucrados en un problema de contrabando, perseguido por entonces por las autoridades reales. Es decir que ni las fluctuaciones económicas ni las numerosas crisis del siglo XVII (caída del régimen de encomienda, decadencia del comercio marítimo de las flotas de galeones...) afectaron la voluntad de la elite local hispano-costarricense de comprar los puestos de cabildo. Por el contrario, nos parece claro que esta voluntad respondió más bien a variables de la cultura política del período como la importancia de los puestos como recompensa y como honores otorgados por la corona como signo de distinción social para la elite.

Las mencionadas constataciones son reforzadas por el hecho de que los puestos de regimiento no recibían ningún sueldo y que eran caros en el contexto (un regimiento costaba más o menos lo mismo que un esclavo africano o que una propiedad de tierras) y, además, que su ejercicio implicaba el abandono al menos parcial de otras actividades quizá más lucrativas. Es decir que era solamente la "ganancia simbólica" lo que empujaba a la elite local a querer apoderarse de los puesto, pues tenía necesidad de ellos para distinguirse socialmente y señalar su poder ante otros grupos de la sociedad colonial. El alto precio del puesto hacía de la compra de un regimiento un hecho improductivo salvo en términos de imagen y prestigio social.

Los puestos de elección anual:

Aún con todo, la venalidad de los puestos no hizo desaparecer totalmente la costumbre medieval de elegir ciertos puestos de cabildo. ${ }^{16}$ Cada año, el primero de enero los regidores debían reunirse para elegir los puestos de justicia (alcaldes ordinarios y de la Santa Hermandad) el procurador síndico y el mayordomo de propios. Estos puestos tenían la misma connotación de compromiso personal y de servicio entre el monarca y los súbditos que tenían los regimientos, por lo que respondieron a los mismos criterios de privilegio y de intercambio de favores contra servicios que hemos estudiado. Era entonces por eso que el acceso a ellos estaba igualmente restringido a un grupo muy selecto de individuos reclutados según sus méritos, riqueza, relaciones familiares y honores. El hecho de ser escogido para ejercer uno de estos puestos implicaba un honor personal de ser nombrado para representar a la corona localmente, pero también era un reconocimiento público del grupo dominante al individuo nombrado, pues significaba una credencial de validación de la pertenencia del escogido a la elite de los poderosos. El poder de ejercer la coerción y su control sobre la cultura escrita dieron gran poder a este grupo de individuos, pues las leyes de Indias establecían que para tener acceso a estos puestos era necesario saber leer y escribir y poseer actividades económicas que permitiesen al titular mantenerse durante el período de ejercicio de su cargo. El puesto anual más poderoso y por ende el más codiciado era el de alcalde ordinario,

16 Lempérière, 76 
pues daba la posibilidad de administrar la justicia y de ejercer coerción. Por ello, daba a su propietario un poder significativo sobre sus semejantes. Es por ello que, como lo señalan numerosos estudios, la corona española prefirió mantener estos puestos como cargos de elección en vez de hacerlos venales y perpetuos. ${ }^{17}$

Su autoridad se extendía en el perímetro urbano e implicaba la función de administrar la justicia en primera instancia, así como de controlar algunos aspectos clave de la vida urbana tales como sustituir al gobernador español en su ausencia, organizar los servicios públicos tales como la venta de víveres y las obras públicas, cobrar los impuestos, distribuir la mano de obra (indígenas de servicio o niños abandonados) y presidir las fiestas públicas. Sus funciones iban entonces desde lo judicial a lo económico e ideológico. Todo ello le daba la posibilidad de organizar la vida urbana a su favor y al de su grupo social así como de recibir emolumentos derivados de su trabajo. En contrapartida, el cargo de alcalde ordinario era un compromiso para quien lo ejerciera pues implicaba el abandono de otras actividades productivas. Por eso mismo, implicaba que su titular debía poseer riquezas suficientes para sobrevivir durante el año de ejercicio.

Los alcaldes ordinarios, así como los de la Santa Hermandad, eran nombrados por pares, un primero y un segundo, sin que nos sea clara la diferencia de funciones entre los dos. ${ }^{18}$ Más bien, la costumbre parece haber respondido a la necesidad de las ciudades coloniales de nombrar una autoridad para los "Vecinos", es decir para aquellos que poseían encomiendas, y otra para los “moradores”, aquellos que no las poseían. En el caso de Costa Rica, esta situación no parece haber sido del todo clara. ${ }^{19}$

Era pues por sus abundantes capacidades, sobre todo coercitivas, que el puesto de alcalde ordinario era el más legislado por el Derecho de Indias.

Las características requeridas por las leyes de Indias para los puestos de alcaldes ordinarios tendían, como en el caso de los regidores, a restringir el acceso a este puesto a un grupo muy selecto de individuos. Por ejemplo, era necesario saber leer y escribir y ser descendiente de los primeros conquistadores. ${ }^{20}$ Esto, sabiendo como lo sabemos que en la época la mayoría de la población era analfabeta, estas disposiciones hacían los cargos de justicia ordinaria un patrimonio exclusivo de un grupo de elite. Además, la disposición de preferir a los miembros de familias de conquistadores tenía el mismo efecto. Esto era, francamente contradictorio con la ley que exigía a los regidores no votar nunca por los miembros de sus familias para este tipo de puestos, pues era algo implícito en la legislación que debían salir todos del mismo medio social. $^{21}$

Por otra parte, la corona prohibía la reelección consecutiva y de más de dos veces de los mismos candidatos en los puestos de justicia ordinaria con el fin de evitar la formación de 17 Ibid

18 Libro IV, Título X, Ley I

19 Zúñiga, “Espagnols”, cap. 5

20 Libro V, Título III, Ley IV, ley de Carlos V, 1536; Libro V, Título III, Ley V, ley de Felipe II, 1565

21 Libro IV, Título IX, Ley XIII, ley de Felipe III, 1609 
grupos cerrados de individuos que monopolizasen los cargos coercitivos. ${ }^{22}$

De la misma forma, este marco legal apuntaba a garantizar los ingresos del rey así como su soberanía, pues prohibía nombrar en los puestos a personas que tuviesen deudas con la corona o que poseyesen puestos venales de la administración real.

Finalmente, los individuos nombrados como alcaldes ordinarios debían residir por fuerza en la localidad de su ejercicio y les estaba prohibido emprender negocios o actividades económicas en los ramos que se suponía debían administrar. ${ }^{23}$

La Santa Hermandad, por su parte, tenía la función de administrar la justicia pero no en el perímetro de la ciudad, sino en las comarcas circundantes, lo que les volvía menos importantes y menos visibles en el núcleo poblado, pero no así en los campos donde tenían ciertamente una importancia notoria. Ellos son, entonces, mucho menos tratados por el Derecho de Indias que los alcaldes ordinarios pero de ninguna manera menos apreciados pues la legislación indiana frecuentemente hace hincapié en la población rural. ${ }^{24}$ El origen de la Santa Hermandad se remonta hasta el siglo XII y la forma en que llegó al nuevo Mundo data de la organización establecida para ella por la reina Isabel de Castilla en el siglo XV..$^{25}$

Los puestos electivos de la época se recubrían también de todo un ceremonial simbólico destinado a subrayar la soberanía real materializada ante la sociedad en su conjunto bajo la forma del ejercicio de la justicia a través de los delegados reales. Uno de estos símbolos, caro por cierto a los oficiales de cabildo, era la "vara de la real justicia" una especie de bastón de mando que actuaba como insignia de la soberanía real otorgada por el cabildo a sus oficiales al momento de su juramentación.

Por su parte, los otros oficiales de cabildo eran también menos tratados por el Derecho de Indias, aún si eran socialmente percibidos como honores, al igual que los cargos de justicia y que implicaban también la posesión de ciertas características sociales negadas al resto de la población, como por ejemplo el conocimiento de la cultura escrita, del derecho, de la manera de llevar libros de cuentas, etc., así como de la capacidad económica de sostenerse durante el ejercicio de sus cargos. El primero de ellos era el "procurador síndico" encargado de representar a la comunidad urbana ante el cabildo y de someter a su consideración las necesidades de la ciudad. ${ }^{26}$ El segundo de ellos, el "mayordomo de propios”, tenía bajo su responsabilidad la administración del presupuesto municipal. ${ }^{27}$

La elección anual de estos oficiales municipales se realizaba el primero de enero de cada año

22 Libro IV, Título IX, Ley XIII, ley de Felipe III, 1609

23 Libro V, Título III, Ley VIII, Carlos V 1554; Libro IV, Título X, Ley XI

24 Libro V, Título III, Ley I, ley de Felipe III, 1631; Ley de Felipe IV, 1646, refrendada en 1650

25 Colin M. McLachlan, La Justicia criminal del siglo XVIII en México: un estudio sobre el tribunal de La Acordada (México: Secretaría de educación pública, 1976), 21-22; véase también Hagen Schulze, Estado y nación en Europa, (Barcelona: Crítica, 1997), 42

26 Libro IV, Título XI, Ley I

27 Libro IV, Título XIII legisla sobre el tema de los fondos de propios; La ley II, Libro IV, Título VII dice que tiene que haber un mayordomo en toda ciudad, pero no dice de qué tipo. 
y el Derecho de Indias la protegía de toda intromisión de los poderes reales. Los regidores votaban en secreto escribiendo sobre papeles en blanco el nombre de los candidatos que proponían para cada puesto. Luego, los papeles eran leídos por el gobernador o por un escribano y aprobados por el representante de la metrópoli.

La elección se revestía también de un ceremonial simbólico destinado a salvaguardar la paz social a través de la pureza del procedimiento y de subrayar las distancias sociales en boga, especialmente la sumisión al monarca y la sanción religiosa aportada por la fe y por la iglesia. Estos valores se evidenciaban durante la ceremonia del juramento de los nuevos oficiales que recibían las "varas de real justicia” de manos de los regidores con la aprobación del gobernador colonial.

Los intereses económicos reales eran también salvaguardados durante la ceremonia, pues los nombrados se debían comprometer a pagar los impuestos reales para obtener los puestos. La elección del día de año nuevo tenía también la función de establecer la concordia y el equilibrio entre la elite local y la corona a través de su representante en la localidad: el gobernador colonial. En este contexto, el gobernador español funcionaba de manera próxima al corregidor de la España moderna: como el representante de la corona al interior del poder local el cual él presidía y ante el cual actuaba como árbitro de las controversias en las votaciones y como fuente de legitimidad de los poderes otorgados por la corporación urbana. Su función no era, entonces, imponer un poder central sobre el poder local, sino garantizar la paz entre los grupos sociales presentes en la sociedad del Antiguo Régimen incluida la que debía existir entre la corona y los poderes locales. Esta última función se echaba a andar pues cabildo y gobernador, poder local y poder central, se interpenetraban el uno al otro y cogobernaban de manera equivalente, de modo que se balanceaban para establecer una concordia y una coordinación entre la corona y el municipio.

Los códigos sociales de acceso al poder en la sociedad colonial: lo que las leyes dicen y lo que las leyes no dicen:

Vistas las evidencias anteriores y a guisa de síntesis, se puede proponer que el Derecho de la época era la expresión de un sistema de valores y representaciones sociales que hacía hincapié en el privilegio y la desigualdad como hechos naturales y hasta queridos por Dios. Al mismo tiempo, al lado de las leyes formales había todo un conjunto de códigos informales que estaban a veces implícitos en el Derecho, y que tenían tanto peso como este para la formación de los grupos dotados de poder político en la época. Este conjunto de códigos formales e informales actuaban en la época como criterios de integración y de exclusión de los grupos poderosos coloniales hispanoamericanos y determinaron la existencia de un sistema aristocrático de ejercicio del poder que lo reservaba solamente a las capas sociales más elevadas. Era entonces el proceso jurídico de creación de una sociedad de estamentos. De esta manera, la cultura socio jurídica de la época garantizaba a los grupos dominantes locales el control exclusivo del poder 
a través de lo que se podría llamar el "monopolio de la posición social.” Tal monopolio era concedido socialmente y sancionado jurídicamente a ciertos sectores de la sociedad mientras que era sistemáticamente negado a los otros.

Tal manera de ver el mundo de lo social fue entronizada en la sociedad de "Antiguo Régimen" puesto que el sistema de representaciones de la época exigía que las autoridades fuesen las gentes más "honestas y capaces” de la sociedad, por ende, gentes de buena conducta, honorables y de capacidad demostrada para ejercer los puestos. En consecuencia, en una sociedad que reconocía la desigualdad como un hecho natural y divinamente sancionado, debía haber un grupo social distinguido por su capacidad de ejercer la autoridad en función de sus condiciones superiores de nobleza. Eso quería decir, en el imaginario dominante de la sociedad de la época., que las gentes dotadas de poder político debían provenir del estamento social más elevado, pues la virtud se asociaba a la calidad del linaje. De esta forma los "vecinos principales de la república” eran el grupo naturalmente llamado a gobernar pues eran "los mejores" de la sociedad. ${ }^{28}$

La sociedad colonial se estructuraba, entonces, alrededor de principios muy estables de autoridad y desigualdad, donde el respeto de las jerarquías y los roles sociales de cada grupo era visto como condición indispensable para mantener la paz social. Estas jerarquías eran vistas como verdades instituidas por Dios para fundar la república cristiana. ${ }^{29}$

Consecuentemente, se creía que, a una mayor calidad social de los dirigentes políticos correspondía una mayor capacidad de llevar al éxito a los otros grupos de la sociedad. Entonces, la ascendencia de un individuo era su mejor garantía de buena conducta cívica. Ello equivale a decir que aquellos que no tenían una ascendencia privilegiada no eran considerados capaces de ejercer cargos de autoridad.

Tal universo mental tuvo repercusiones capitales para el estilo de vida de los sectores dominantes que fue definido a partir de un ideal de "valer más" o de "vivir noblemente" que no era sino la conjunción del éxito económico con la distinción a través de la acumulación de honores y riquezas. La ostentación de todo ello era, entonces, una herramienta para señalar el poder y la preeminencia social de los grupos dominantes hispanoamericanos que les servía al mismo tiempo para excluir de ello a los dominados. ${ }^{30}$

Pero este "monopolio de la posición social" puede ser descompuesto en varios monopolios menores. El primero de ellos, podría ser llamado el "monopolio de la riqueza." Dado que los candidatos a poseer puestos políticos frecuentemente debían pagar por ellos y poseer medios económicos para sostenerse mientras los ejercían, la posesión de riquezas era una condición indispensable para el acceso al poder que estaba entonces fuera de alcance para los grupos inferiores de la época. Ello llevaba a creer que si “los mejores” eran al mismo tiempo los más

$\begin{array}{ll}28 & \text { Lempérière,.32 y } 45 \\ 29 & \text { Imízcoz, 31-66 } \\ 30 & \text { Zúñiga, “Cabildo colonial”, 12-21. }\end{array}$


ricos, la riqueza per se era garantía de capacidad para ejercer los cargos. En consecuencia, los ricos debían hacer ostentación de su riqueza como marca de su jerarquía social y política. La utilización social de signos externos de status era, pues, capital en esta sociedad.

El segundo monopolio que puede desgranarse del sistema de valores que tratamos es el “monopolio de las relaciones”. Era precisamente un conjunto de lazos sociales lo que daba poder a los grupos dominantes. El primer lazo, como lo hemos visto, era la pertenencia a un estamento social privilegiado y dirigente. El segundo lazo fundamental era la pertenencia a instituciones políticas, especialmente al cabildo, pues esto recortaba drásticamente a los miembros del grupo dirigente del resto de la sociedad que le rodeaba. El tercer lazo social fundador del poder de los grupos dominantes hispanoamericanos era el lazo familiar. Ya el Derecho de Indias establecía que, para tener acceso a los puestos políticos del Nuevo Mundo era necesario ser descendiente de los primeros conquistadores o bien miembro de una familia honorable que hubiese tenido anteriormente puestos políticos o poseer méritos suficientes en opinión de la corona. De entrada, esto determinó que la pertenencia a familias de las capas sociales altas y distinguidas por generaciones de detentar el poder político fuese para la corona una condición determinante del acceso al poder. En consecuencia, es previsible que la tendencia de estas familias fuese a unirse entre ellas para amalgamar sus poderes, sus glorias y sus patrimonios y para excluir de ellos, en el extremo opuesto, a los grupos subordinados de la sociedad colonial. Esto hizo de la familia un criterio de integración y de exclusión de las elites coloniales hispanoamericanas. Los lazos familiares operaban también de manera indirecta, pues los individuos podían reclamar privilegios en función de los méritos de sus cónyuges. Pero la pertenencia familiar implicaba muchos conflictos. Entre los conquistadores, determinaba la utilización de un criterio de precedencia en las nominaciones para los puestos políticos pues, entre individuos que tenían el mismo derecho en función de sus servicios de conquista, el único criterio válido para escoger de entre ellos a los más meritorios era el orden de llegada. Pero entre conquistadores y no conquistadores el criterio era significativamente más ambiguo pues la corona favorecía también a los recién llegados que poseyeran condiciones de nobleza, méritos diversos y relaciones de dependencia con personajes distinguidos tal como los virreyes, los obispos y los gobernadores coloniales. Para aclarar las vías de acción cuando se trataba de escoger individuos meritorios para puestos políticos, la corona hacía recurso a criterios de calidad social presentes en el imaginario de la España de la época. Por ejemplo, la "limpieza de sangre" o el hecho de ser "cristiano viejo" tenía un peso para señalar a los miembros políticamente elegibles de los estratos dominantes. La blancura de la piel era también una forma de reconocer a aquellos que servían para ser nominados para dirigir la sociedad. La distinción explícita de nobleza, donde existía, operaba también como título de pertenencia al grupo llamado a gobernar.

El tercer monopolio derivado del derecho y del imaginario de la época para el reclutamiento de los grupos dirigentes era el "monopolio de las armas.” Los méritos guerreros eran muy importantes en la sociedad de la Europa medieval y moderna pues la conquista era un criterio 
de ennoblecimiento empleado por los reyes para estimular y recompensar la participación de sus súbditos en la guerra. ${ }^{31}$ Este molde mental se reprodujo en las guerras de conquista del Nuevo Mundo que fueron entonces percibidas como una fuente de ennoblecimiento para aquellos que no tenían alternativas para alcanzar el estatuto de nobleza en la península ibérica después de la "Reconquista."32 En consecuencia, después de la conquista la participación en guerras contra los piratas y los indígenas insumisos siguió siendo un criterio fundamental para el reclutamiento de los grupos dotados de poder político en la América Hispánica. Entonces, la participación en los ejércitos y armadas reales y en las milicias coloniales y en campañas guerreras se volvió un asunto central para las elites coloniales que las hacían valer todo el tiempo en sus probanzas de méritos y servicios.”

El último monopolio que determinaba la construcción de los grupos dominantes hispanoamericanos de le época estudiada era el que podríamos llamar el "monopolio del saber." El derecho de Indias establecía que, para tener puestos de cabildo, era requisito saber leer y escribir. Además, los miembros de los cabildos hispanoamericanos, según sus funciones, debían poseer conocimientos prácticos de derecho para administrar los asuntos políticos de sus localidades y para instruir procesos judiciales, así como conocimientos técnicos para llevar los asuntos financieros de la corporación urbana. La posesión de estos "saberes" debe haber hecho de los miembros del poder local un grupo muy poderoso comparado con otros sectores de la sociedad colonial, pues la mayoría de las gentes eran analfabetas en la época. Además ello les daba el poder de instruir procesos judiciales, de emitir documentos legales de gobierno y de comunicarse con las instancias superiores del aparato político administrativo colonial, hechos todos imposibles para otros grupos de la sociedad de la época.

\section{Conclusión:}

Para sintetizar, era una suma de relaciones, privilegios y conocimientos lo que hacía de los miembros de un cabildo un grupo distinguido y netamente recortado de otros en la época, el único dotado para dirigir. En contrapartida, los otros grupos de la sociedad colonial eran sistemáticamente marginados de este abanico de virtudes. Por ende, los miembros de un cabildo hispanoamericano eran sin duda un grupo de poder, dotado de una capacidad de acción que dirigía a los otros y cuyas decisiones afectaban al resto de la comunidad. Ello fue así porque los criterios de pertenencia a la institución funcionaban en torno a conceptos de nobleza, sangre, mérito y riqueza. Nos encontramos, entonces, ante una sociedad de ideales señoriales que estructuró para ella misma un régimen de gobierno aristocrático. En contrapartida, el poder político servía también como elemento estructurante de las elites coloniales pues la pertenencia al grupo privilegiado tenía por condición la posesión de un cargo político.

31 Zúñiga, “Espagnols”, caps. VI y VII

32 Juan Marchena, Ejército y milicias en el mundo colonial hispanoamericano, (Sevilla: Escuela de Estudios Hispanoamericanos, 1998), cap.1 
Indexaciones: Repositorio de Revistas UCR, DIALNET, Latindex, REDALYC Directorio y recolector de recursos digitales del Ministerio de Cultura de España, Directory of Open Access Journals. Diálogos Revista Electrónica de Historia ISSN 1409-469X. Número especial 2008. Dirección web: http://historia.fcs.ucr.ac.cr/dialogos.htm

Dentro de este contexto, el cabildo se insertaba en la estructura más vasta del aparato político español del Nuevo Mundo en dependencia de una relación personal de reciprocidad donde las elites locales tenían necesidad del monarca para obtener de él el poder y la legitimidad, y el rey obtenía de los grupos locales su fidelidad para administrar las colonias a través de una constante transacción de favores contra servicios. 